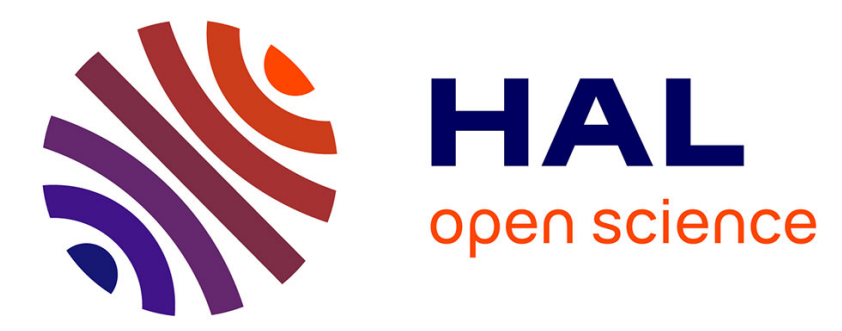

\title{
Validation of the new AJCC TNM staging system for gastric cancer in a large cohort of patients $(n=2,155)$ : focus on the $T$ category
}

A. Marchet, S. Mocellin, A. Ambrosi, P. Morgagni, G. Vittimberga, F. Roviello, D. Marrelli, G. de Manzoni, A. Minicozzi, A. Coniglio, et al.

\section{To cite this version:}

A. Marchet, S. Mocellin, A. Ambrosi, P. Morgagni, G. Vittimberga, et al.. Validation of the new AJCC TNM staging system for gastric cancer in a large cohort of patients $(n=2,155)$ : focus on the T category. EJSO - European Journal of Surgical Oncology, 2011, 37 (9), pp.779. 10.1016/j.ejso.2011.06.001 . hal-00723459

\section{HAL Id: hal-00723459 \\ https://hal.science/hal-00723459}

Submitted on 10 Aug 2012

HAL is a multi-disciplinary open access archive for the deposit and dissemination of scientific research documents, whether they are published or not. The documents may come from teaching and research institutions in France or abroad, or from public or private research centers.
L'archive ouverte pluridisciplinaire HAL, est destinée au dépôt et à la diffusion de documents scientifiques de niveau recherche, publiés ou non, émanant des établissements d'enseignement et de recherche français ou étrangers, des laboratoires publics ou privés. 


\section{Accepted Manuscript}

Title: Validation of the new AJCC TNM staging system for gastric cancer in a large cohort of patients $(n=2,155)$ : focus on the T category

Authors: A. Marchet, MD S. Mocellin, MD A. Ambrosi, PhD P. Morgagni, MD G.

Vittimberga, MD F. Roviello, MD D. Marrelli, MD G. de Manzoni, MD A. Minicozzi, MD

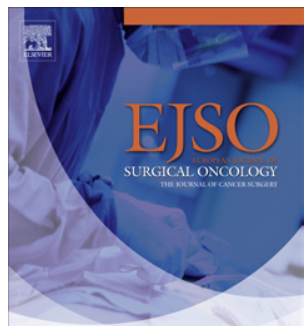

A. Coniglio, MD G. Tiberio, MD F. Pacelli, MD F. Rosa, MD D. Nitti, MD

PII:

S0748-7983(11)00316-7

DOI:

10.1016/j.ejso.2011.06.001

Reference: YEJSO 3175

To appear in: European Journal of Surgical Oncology

Accepted Date: 13 June 2011

Please cite this article as: Marchet A, Mocellin S, Ambrosi A, Morgagni P, Vittimberga G, Roviello $F$, Marrelli D, de Manzoni G, Minicozzi A, Coniglio A, Tiberio G, Pacelli F, Rosa F, Nitti D. Validation of the new AJCC TNM staging system for gastric cancer in a large cohort of patients $(n=2,155)$ : focus on the T category, European Journal of Surgical Oncology (2011), doi: 10.1016/j.ejso.2011.06.001

This is a PDF file of an unedited manuscript that has been accepted for publication. As a service to our customers we are providing this early version of the manuscript. The manuscript will undergo copyediting, typesetting, and review of the resulting proof before it is published in its final form. Please note that during the production process errors may be discovered which could affect the content, and all legal disclaimers that apply to the journal pertain. 
Original article

\section{Validation of the new AJCC TNM staging system for gastric cancer in a large cohort of patients $(n=2,155)$ : focus on the $T$ category}

A. Marchet, $\mathrm{MD}^{1}$, S. Mocellin, $\mathrm{MD}^{1}$, A. Ambrosi, $\mathrm{PhD}^{2}$, P. Morgagni, MD ${ }^{3}$, G. Vittimberga,

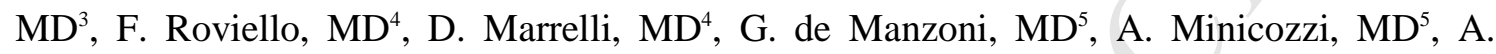
Coniglio, $\mathrm{MD}^{6}$, G. Tiberio, $\mathrm{MD}^{6}$, F. Pacelli, $\mathrm{MD}^{7}, \mathrm{~F}$. Rosa, $\mathrm{MD}^{7}$, and D. Nitti, $\mathrm{MD}^{1}$.

On behalf of the Italian Research Group for Gastric Cancer (G.I.R.C.G.).

${ }^{1}$ Clinica Chirurgica II, Department of Oncological and Surgical Sciences, University of Padova, Padova, Italy

${ }^{2}$ Statistics Center for Biomedical Sciences, San Raffaele University, Milan, Italy

${ }^{3}$ Department of General Surgery, Morgagni-Pierantoni Hospital, Forlì, Italy

${ }^{4}$ Surgical Oncology Unit, University of Siena, Siena, Italy

${ }^{5}$ First Division of General surgery, University of Verona, Verona, Italy

${ }^{6}$ Institute of Clinica Chirurgica, University of Brescia, Brescia, Italy

${ }^{7}$ Institute of Clinica Chirurgica, Department of Chirurgia Digestiva, Cattolica University of Rome, Rome, Italy

Correspondence to: Alberto Marchet, MD, Clinica Chirurgica II, Dipartimento di Scienze Oncologiche e Chirurgiche, Università di Padova, Via Giustiniani 2, 35128 Padova, Italy.

Tel: +39049 8212055, Fax: +39049651891

E-mail: marchet@unipd.it 


\section{ABSTRACT}

Background. The prognostic value of $\mathrm{T}$ subclassification in patients with gastric carcinoma has been just implemented in the new AJCC TNM staging system, which has reclassified T2a and T2b into T2 and T3 tumors, respectively. The aim of the present study was to validate the prognostic significance of the new $\mathrm{T}$ categorization within the frame of the latest TNM staging system.

Methods. We retrospectively reviewed the records of $686 \mathrm{~T} 2 / \mathrm{T} 3$ patients among 2,155 subjects who underwent radical resection for gastric carcinoma at six Italian centers from 1988 through 2006.

Results. Upon multivariate analysis, the new $\mathrm{T}$ categories, extent of lymph node dissection (D) and patient's age were retained by the survival model as independent prognostic factors. In particular, the death risk for patients with T3 tumors was higher than that of patients with T2 tumors (HR: 1.42, $\mathrm{P}=0.005)$.

Among the 686 patients previously classified as having T2 tumors, patients with T2 and T3 disease were $270(39.4 \%)$ and $416(60.6 \%)$, respectively. After a median follow-up of 55 months, the 5-year overall survival rates were $67.3 \%$ and $52.3 \%$ for patients with T2 and T3 tumors, respectively $(\mathrm{P}<0.001)$. The survival advantage for the $\mathrm{T} 2$ as compared to $\mathrm{T} 3$ category was maintained even when $\mathrm{NO}$ and $\mathrm{N}+$ patients were separately considered $(\mathrm{P}=0.0154$ and $\mathrm{P}<0.001$, respectively).

Conclusions. Our data confirm the prognostic difference between the newly proposed $\mathrm{T} 2$ and T3 categories, which should be implemented in the routine clinical practice to improve risk stratification of patients with gastric cancer.

Keywords: gastric cancer, TNM staging system, prognostic factors, survival analysis. 


\section{INTRODUCTION}

The prognosis of resectable gastric cancer is mainly related to the depth of invasion ( $\mathrm{T}$ category) and lymph node involvement (N category) (1-4). Following the International Union Against Cancer-American Joint Committee on Cancer (UICC-AJCC) TNM classification released in 2002 (5), the T2 category - which is defined as a tumor involving the muscularis propria or subserosa $(5,6)$ - is considered advanced disease but represents a stage with an intermediate prognosis between early gastric cancer (EGC, T1) and serosal involvement gastric carcinoma (T3). Whereas the survival rates of EGC are high (independently of the lymph node status) (7-9) and those of $\mathrm{T} 3$ are low $(1,2,10)$, the survival rate of $\mathrm{T} 2$ gastric cancer varies significantly in relation to other prognostic parameters (i.e. nodal metastasis) (11-16). Since 1998, the College of American Pathologists suggested that a subclassification of $\mathrm{T} 2$ into $\mathrm{T} 2 \mathrm{a}$ (tumor with invasion of muscolaris propria) and T2b (tumor with invasion of subserosa) should be recommended because "postsurgical survival after resection for cure is significantly different for patients with T2a and T2b lesions" (17).

The prognostic role of $\mathrm{T} 2$ subclassification is supported by several lines of evidence. In particular, this $\mathrm{T}$ category has been associated with variable nodal involvement rates, $\mathrm{N}$-ratio values as well recurrence and mortality rates. It is unclear whether these findings depend upon the extent of lymphadenectomy $(11,12,18,19)$. In a recently published study performed on 189 patients curatively resected with extended lymphadenectomy, we confirmed that patients with T2a tumors have a significantly better 5-year overall survival as compared to those with T2b neoplasms, with $\mathrm{T} 2$ subcategorization being an independent prognostic value at multivariate analysis (20).

Although the 2002 UICC-AJCC classification split the T2 category into T2a and T2b, these subcategories were not maintained in the TNM stage grouping (5). In the light of the above mentioned evidence regarding the prognostic value of $\mathrm{T} 2$ subcategorization, this gap of the 
2002 TNM version will be filled by the 2010 TNM release. In particular, the new version redefines the $\mathrm{T}$ category as follows: $\mathrm{T} 1 \mathrm{a}=$ mucosa, $\mathrm{T} 1 \mathrm{~b}=$ submucosa, $\mathrm{T} 2=$ muscolaris propria, $\mathrm{T} 3=$ subserosa (formerly known as $\mathrm{T} 2 \mathrm{~b}$ ), $\mathrm{T} 4 \mathrm{a}=$ perforates the serosa (formerly known as T3), T4b = infiltration of adjacent structures (formerly known as T4) (21). In the present multicentric study we confirm that the subdivision of the T2 category (T2 and T3 in the new TNM classification) has a significant prognostic value independently of lymph node status in patients with gastric cancer.

\section{PATIENTS AND METHODS}

\section{Patients selection and data collection}

In this retrospective multicentric study, data were collected from the medical records of 2,155 patients who underwent radical resection (R0) for histologically confirmed T1-T4a gastric carcinoma from January 1988 through December 2006. Patients were operated at six Italian centers experienced in gastric cancer treatment: Clinica Chirurgica Generale 2, University of Padova ( $\mathrm{n}=352)$; First Division of General Surgery, University of Verona $(\mathrm{n}=387)$, Institute of Surgical Sciences, University of Siena $(n=391)$, "Morgagni” Hospital of Forlì ( $n=648)$; Institute of Clinica Chirurgica, University of Brescia ( $\mathrm{n}=230)$; Institute of Clinica Chirurgica, Cattolica University of Rome $(n=147)$.

Eligibility criteria included histologically confirmed R0 gastric resection and pathological evaluation of the total number of resected lymph nodes as well as the number of metastatic lymph nodes. Patients with inadequate number of lymph nodes resected (less than 16 lymph nodes, as required by the AJCC TNM classification for the definition of the N3b category, see below) were excluded from the analysis. Patients with distant metastases (as assessed by thoracic and abdominal CT-scan), tumors of the gastric stump after gastric resection for 
benign disease and T4b tumors were also excluded from the analysis. Patients dead in the post-operative period were also excluded.

Depth of primary tumor invasion (pT1a/b, pT2 [muscolaris propria], pT3 [subserosa], and pT4a [serosa] $)$ and lymph node involvement $(\mathrm{N} 0=$ no metastasis, $\mathrm{N} 1=1$ to 2 metastatic lymph nodes, $\mathrm{N} 2=3$ to 6 metastatic lymph nodes, N3a $=7$ to 15 metastatic lymph nodes, $\mathrm{N} 3 \mathrm{~b}=16$ or more metastatic lymph nodes) were classified according to the 2010 UICC/AJCC TNM classification (21).

Following the Japanese Classification of Gastric Carcinoma (JCGC) guidelines (6), lymphadenectomy was classified as D1, D2 or D3. In each center the nodal status was assessed by the same pathologist, who also reviewed the slides of all primary tumors. A central pathologic review was employed in the doubtful cases to avoid the single institutional bias.

For all patients, regular 6-month follow-up consisted of physical examination, serum tumor biomarkers, radiological imaging (thoraco-abdominal CT-scan), endoscopic control and chart review or telephone interview.

The final date of follow-up was December 2009 and the median follow-up after surgery was 55 months (range: 3-240 months).

\section{Statistical analysis}

Statistical analysis and graphics were performed in the "R" environment version 2.9 (www.Rproject.org) and with the SPSS statistical package (SPSS Inc., Chicago, IL). Overall survival (OS) rates and 95\% confidence intervals (CI) were determined using the Kaplan-Meier method (22), the event being defined as death for any cause. The log-rank test was used to identify differences between the survival estimates of different patients' groups (23).

The following independent variables were analyzed for the 686 patients classified as T2 and T3 categories: 1) age (<65 years $v s \geq 65$ years); 2) sex (male $v s$ female); 3) tumor site (cardia 
vs upper third $v s$ middle third $v s$ lower third $v s$ multicentric); 4) type of surgical resection (subtotal gastric resection $v s$ total gastrectomy $v s$ extended total gastrectomy); 5) extension of lymphadenectomy (D1 vs D2 vs D3); 6) grading (G1 vs G2 vs G3 vs G4 vs unknown); 7) Lauren type (intestinal $v s$ diffuse $v s$ mixed); 8) T-stage (T1a [mucosa] vs T1b [submucosa] $v s$ T2 [muscolaris propria] vs T3 [subserosa] vs T4a [serosa]); 9) number of metastatic lymph nodes (N0 vs $\mathrm{N} 1$ vs $\mathrm{N} 2$ vs $\mathrm{N} 3 \mathrm{a} v s \mathrm{~N} 3 \mathrm{~b})$.

Spline functions were fitted to evaluate the relationship between the number of metastatic lymph nodes and the number of examined nodes in the different $\mathrm{T}$ categories.

At multivariate analysis, all the above mentioned variables were considered. The Cox's proportional hazards model was selected by means of a stepwise procedure (23). For all analyses, only P-values $<0.05$ were considered significant.

\section{RESULTS}

Patients and tumor characteristics

Clinical and pathological data of 686 patients classified T2/T3 are shown in Table 1.

The male-to-female ratio was approximately 3:2, with a median (range) age of 69 (27-94) years. In $39 \%$ of patients the tumor was limited to the muscolaris propria (T2), while in the remaining $61 \%$ of cases the tumor involved the subserosa (T3). A D2 or more extended lymphadenectomy was performed in $86 \%$ of patients, while a D1 lymphadenectomy was performed in $14 \%$ of patients.

The distribution of $\mathrm{T} 2$ and $\mathrm{T} 3$ was similar for age and sex $(\mathrm{P}=0.104$ and $\mathrm{P}=0.610)$ (Table 1). By contrast, grade, site and Lauren type of primary tumor, surgical procedure and extent of lymphadenectomy had a statistically different distribution between T2 and T3 patients (all P- 
values $<0.05)$. Adjuvant chemotherapy was performed only for node-positive patients with similar percentages in $\mathrm{T} 2$ and $\mathrm{T} 3$ patients $(35 \%$ vs $38 \%, \mathrm{P}=0.57)$.

The median number of lymph nodes removed and examined was 28 (range 16-121).

Non-parametric analysis by means of spline functions showed that in patients with T2 tumors the number of metastatic lymph nodes was not influenced by the number of nodes examined (Figure 1). However, for T3 and T4a tumors the number of metastatic lymph nodes increased as a function of the number of examined nodes (Figure 1).

Nodal involvement according to depth of invasion of the primary tumor is shown in Table 1 and Table 2. Out of 270 patients with T2 disease, $46 \%$ had lymph node involvement $(\mathrm{N}+)$, compared with $69 \%$ of cases among 416 patients with T3 disease $(P<0.001)$. In particular, the incidence of $\mathrm{N} 1$ disease was similar for $\mathrm{T} 2$ and $\mathrm{T} 3$ categories (19 vs 18\%, respectively; $P=0.686$ ); in contrast the incidence of $\mathrm{N} 2, \mathrm{~N} 3 \mathrm{a}$ and $\mathrm{N} 3 \mathrm{~b}$ was significantly different between T2 and T3 categories (18 vs 25\%, $P=0.031 ; 7$ vs $16 \%, P=0.003 ; 1$ vs $10 \%, \mathrm{P}<0.001$, respectively) (24).

\section{Survival analysis}

At univariate analysis, factors significantly associated with overall survival of $686 \mathrm{~T} 2 / \mathrm{T} 3$ patients were age, extent of lymphadenectomy and T2/T3 stage (Table 1).

Table 3 illustrates the 5-year OS of 686 patients according to T-stage and N-stage.

The 5-year OS rate was 58.3\% (CI: 54.5-62.4) for the 686 patients. For patients with T2 lesions the 5-year OS rate was 67.3\% (CI 61.1-72.8), compared with 52.3\% (CI 47.0-57.4) for T3 cases $(P<0.001)($ Table 1$)$.

When patients were stratified according to $\mathrm{N}$ stage, the 5-year OS rate was $65.7 \%$ (CI: 60.1 71.8) for patients with N0 disease versus $53.1 \%$ (CI: 48.2-58.6) for those with lymph node metastasis $(\mathrm{N}+)$. For patients classified $\mathrm{N}+$, the 5-year overall survival rate was $68.3 \%$ (CI 
60.3-77.4), 53.4\% (CI 45.5-62.6), 45.7\% (CI 35.6-56.8), and 13.9\% (CI 4.8-40.3) for patients with N1, N2, N3a and N3b disease, respectively (Table 1).

Table 3 reported the 5-year OS rate according to T2/T3 category and N category. The 5-year OS rate for $\mathrm{N} 1, \mathrm{~N} 2$ and $\mathrm{N} 3 \mathrm{a}$ categories was not statistically different $(P=0.271)$ for $\mathrm{T} 2$ patients (only 2 patients in the T2 subgroup was classified N3b and therefore the survival rate of this subcategories could not be evaluated); by contrast for the T3 subset, 5-year OS rates were statistically significant different between N1, N2, N3a and N3b disease $(P<0.0001)$. Upon stratification of $\mathrm{T} 2$ and $\mathrm{T} 3$ groups according to the $\mathrm{N}$ stage ( $\mathrm{N} 0$ vs $\mathrm{N}+$ ), 5-year OS rate was greater for T2N0 vs T3N0 (68.0\% vs 63.1\%, P=0.015) (Figure 2, upper panel). Similarly, this difference was statistically significant in favor of $\mathrm{T} 2 \mathrm{~N}+$ with respect of $\mathrm{T} 3 \mathrm{~N}+(66.5 \% \mathrm{vs}$ 47.2\%; P<0.001) (Figure 2, lower panel). The 5-year OS difference observed between patients with $\mathrm{T} 2 \mathrm{~N} 1$ tumors and those with $\mathrm{T} 3 \mathrm{~N} 1$ disease was of borderline significance (71.1\% vs 66.4\%; $P=0.076$ ). The 5-year OS rate of patients with $\mathrm{T} 2 \mathrm{~N} 2$ was not different from that of patients with T3N2 disease $(61 \%$ vs $49.9 \%, \mathrm{P}=0.264)$. Finally the 5-year OS rates of T2N3a vs T3N3a patients were $76.0 \%$ and $39.1 \%$, respectively $(\mathrm{P}=0.0328)$.

At multivariate analysis age, extent of lymphadenectomy and $\mathrm{T}$ stage were retained as independent prognostic factors for the 686 patients (Table 4). The mortality risk for T3 patients was significantly higher than that of patients with T2 tumors (HR: $1.420 ; \mathrm{P}=0.005$ ).

\section{DISCUSSION}

In this retrospective study, which involved six Italian centers experienced in gastric cancer surgery, we investigated the prognostic impact of the new $\mathrm{T}$ categories recently implemented in the latest version of the AJCC TNM classification (21), with special attention to the T2 and T3 (formerly T2a and T2b) subcategories, in patients who underwent radical resection for gastric carcinoma. Univariate analysis demonstrated that the 5-years OS rate of patients with 
T2 tumors was significantly higher than that of patients with T3 tumors; moreover, at multivariate analysis, the risk of death associated with T2 tumors was significantly lower than that of $\mathrm{T} 3$ tumors.

\section{T category distribution}

In our experience, the occurrence of $\mathrm{T} 2 / \mathrm{T} 3$ tumors was $32 \%$ among 2,155 R0 patients. In the study published by Fotia et al., among 624 radically resected gastric cancer patients the incidence of T2/T3 neoplasms was 29\% (14); similarly, Sarela et al. reported a $30 \%$ incidence of T2/T3 tumors (11). In some Japanese series, the incidence of T2/T3 neoplasms ranges from $10 \%$ to $38 \%(12,13,18,19)$. Moreover, in our study the tumors were classified as $\mathrm{T} 2$ in $12 \%$ and $\mathrm{T} 3$ in $19 \%$ of cases. The different proportions of $\mathrm{T} 2$ versus $\mathrm{T} 3$ tumors and $\mathrm{T} 3$ versus $\mathrm{T} 4 \mathrm{a}$ tumors reported in the literature $(2,25)$ may reflect the accuracy of pathological evaluation and the pathologist's attitude to differentiate a real involvement of the serosa (T4a) from the cases in which the infiltration is limited to the subserosa (T3).

\section{Relationship between $T$ and the $N$ category}

Using the UICC/AJCC classification, some investigators observed a different correlation between the T2 and T3 gastric wall involvement and the $\mathrm{N}$ category (11-14). In our experience the number of metastatic nodes appears to be influenced by the number of examined nodes only for T3 and T4a tumors; however, we did not observe such a correlation for T2 tumors, which supports the different behavior of T2 as compared to T3 neoplasms.

On the other side, we observed a statistically different association between $\mathrm{T}$ and $\mathrm{N}$ category: in particular, lymph node involvement rate was significantly lower (45\%) in T2 cases as compared to T3 cases (69\%). The incidence of N1 cases was similar for T2 and T3 patients whereas the $\mathrm{N} 2$ and $\mathrm{N} 3 \mathrm{a}$ categories resulted significantly more frequent among T3 patients. 


\section{Survival findings}

Considering the data reported in the international literature, there is no agreement regarding the survival of T2/T3 patients. In the study by Sarela et al., a significantly better 5-year survival was reported for T2 patients with respect of T3 cases (64\% vs 46\%, P=0.005) (11). However, in a subgroup analysis considering only patients with "adequately staged" disease (more than 15 lymph node examined), the same Author reported different results: the 5-year survival rates of patients with N0 disease were similar among T2 and T3 patients (90\% vs $86 \%, \mathrm{P}=0.8$ ) and the 5-year survival rates of patients with $\mathrm{N} 1$ disease were not statistically different between $\mathrm{T} 2$ and $\mathrm{T} 3$ cases (56\% vs $44 \%, \mathrm{P}=0.3)$ (11). Finally, at multivariate analysis, Sarela et al. found that $\mathrm{N}$ category and site of primary tumor (but not depth of mural invasion) were independent factors predictive of disease specific death (11).

Similar conclusions were drawn by Fotia et al.: in a study on 182 T2/T3 radically resected gastric cancer patients, they found no statistically different survival between T2 and T3 patients (74\% vs $67 \%$ 5-year survival, respectively; $\mathrm{P}=0.2)$ and these categories were not retained as independent prognostic factors at multivariate analysis (14).

In a recent study on 192 radically resected T2/T3 patients, we found that the prognosis of patients classified T2 is significantly better as compared to those classified T3, the 5-year OS rate being $73 \%$ vs $31 \%(\mathrm{P}<0.001)(20)$. At multivariate analysis, T-stage (including the T2/T3 subcategories) was retained as an independent prognostic factor and, compared with T1a, the risk of death associated with T3 tumors was statistically greater than that associated with T2 tumors (HR: 1.89 vs 0.97) (20). These results were in line with those reported by Park and coworkers: in a large study (1,118 patients), which included patients with more than 15 lymph nodes removed and examined, they found a statistically significant 5-year survival advantage for $\mathrm{T} 2$ with respect to $\mathrm{T} 3$ tumors $(85 \%$ vs $56 \%, \mathrm{P}<0.001)(12)$. In addition, a significant 
difference in the survival rates between $\mathrm{T} 2$ and $\mathrm{T} 3$ patients was observed when cases were stratified according to the $\mathrm{N}$-stage ( $82 \%$ vs $60 \%$ in patients with $\mathrm{N} 1, \mathrm{P}<0.001 ; 65 \%$ vs $35 \%$ in $\mathrm{N} 2$ cancers, $\mathrm{P}=0.0002$; and $52 \%$ vs $15 \%, \mathrm{P}=0.02$ in $\mathrm{N} 3$ cases) (12). The same investigators found that the TNM classification including the T2/T3 subcategories was significantly associated with prognosis at multivariate analysis (12).

In the present large multicentric study we confirmed the prognostic value of T2/T3 categories: the 5-year OS of T2 patients was $67 \%$, compared with $52 \%$ for T3 cases $(P<0.001)$. A statistically significant survival advantage was maintained when $\mathrm{T}$ and $\mathrm{N}$ subcategories were considered: 5-year OS was greater for T2 N0 vs T3 N0 (68\% vs 63\%, $\mathrm{P}=0.015)$ and for T2 N+ with respect of $\mathrm{T} 3 \mathrm{~N}+(66 \%$ vs $47 \% ; P<0.001)$. This difference was not maintained for all $\mathrm{N}$ subcategories, but this could well be due to the relatively small sample size of subgroups. Moreover, the risk of death associated with $\mathrm{T} 2$ tumors was significantly lower than that associated with T3 tumors.

In conclusion, the new $\mathrm{T}$ category of UICC/AJCC classification can effectively stratify subgroups of patients with gastric cancer. These homogeneous classes of risk are independent of lymph nodes involvement: this finding could be particularly useful considering the different extent of lymph node dissection performed by surgeons.

According to our results, the new classification of the T category should be implemented in the routine clinical setting as it improves the selection of high risk patients, which can ultimately lead to identify subgroups of patients who most benefit from adjuvant treatment. 


\section{CONFLICT OF INTEREST}

None of the authors has any conflict of interest regarding the manuscript: "Validation of the new AJCC TNM staging system for gastric cancer in a large cohort of patients $(n=2,155)$ : focus on the T category".

\section{ACKNOWLEDGEMENTS}

This study was supported by the Italian Veneto Region Associazione Italiana Ricerca sul Cancro (AIRC) grant 2009.

All Authors had full access to all of the data in the study and takes responsibility for the integrity of the data and the accuracy of the data analysis. 


\section{REFERENCES}

1) Dicken BJ, Bigam DL, Cass C, et al. Gastric adenocarcinoma: review and considerations for future directions. Ann Surg. 2005;241:27-39.

2) Hohenberger P, Gretschel S. Gastric Cancer. Lancet. 2003;362:305-315.

3) Kattan MW, Karpeh MS, Mazumdar M, et al. Postoperative nomogram for disease-specific survival after an R0 resection for gastric carcinoma. J Clin Oncol. 2003;21:3647-3650.

4) Soga K, Ichikawa D, Yasukawa S, et al. Prognostic impact of the width of subserosal invasion in gastric cancer invading the subserosal layer. Surgery. 2010;147:197-203.

5) Greene FL, Page DL, Fleming ID, et al.. AJCC Cancer Staging Manual (6th ed). SpringerVerlag: New York, 2002.

6) Japanese Gastric Cancer Association. Japanese Classification of Gastric Carcinoma. $2^{\text {nd }}$ English ed. Gastric Cancer. 1998;1:10-14.

7) Nomura S, Kaminishi M. Surgical treatment of early gastric cancer. Dig Surg. 2007;24:96100.

8) Roviello F, Rossi S, Marrelli D, et al. Number of lymph node metastases and its prognostic significance in early gastric cancer: a multicenter Italian study. J Surg Oncol. 2006;94:275280.

9) Gotoda T, Yanagisawa A, Sasako M, et al. Incidence of lymph node metastasis from early gastric cancer: estimation with a large number of cases at two larger centers. Gastric Cancer. $2000 ; 3: 219-225$.

10) Baba H, Korenaga D, Haraguchi $M$, et al. Width of serosal invasion and prognosis in advanced human gastric cancer with special reference to the mode of tumor invasion. Cancer. $1989 ; 64: 2482-2486$. 
11) Sarela AI, Turnbull AD, Coit DG, et al. Accurate lymph node staging is of greater prognostic importance than subclassification of the $\mathrm{T} 2$ category for gastric adenocarcinoma. Ann Surg Oncol. 2003;10:783-791.

12) Park do J, Kong SH, Lee HJ, et al. Subclassification of pT2 gastric adenocarcinoma according to depth of invasion (pT2a vs pT2b) and lymph node status. Surgery. 2007;141:757-763.

13) Komatsu S, Ichikawa D, Kurioka H, et al. Prognostic and clinical evaluation of patients with T2 gastric cancer. Hepatogastroenterology. 2005;52:965-968.

14) Fotia G, Marrelli D, De Stefano A, et al. Factors influencing outcome in gastric cancer involving muscolaris and subserosal layer. Eur J Surg Oncol. 2004;30:930-934.

15) Maehara Y, Anai H, Muriguchi S, Watanabe A, et al. Gastric carcinoma invading muscolaris propria and macroscopic appearance. Eur J Surg Oncol. 1992;18:131-134.

16) Wang A, Guo P, Sun Z, Xu H. Clinicopathological variables associated with lymph node metastasis and prognostic factors in pT2 gastric cancer. J Int Med Res. 2009;37:359-366.

17) Compton CC, Sobin LH. Protocol for the examination of specimens removed from patients with gastric carcinoma: a basis for checklists. Members of the Cancer Committee, College of American Pathologists, and the Task Force for Protocols on the Examination of Specimens From Patients With Gastric Cancer. Arch Pathol Lab Med. 1998;122:9-14.

18) Abe S, Yoshimura H, Nagoaka S, et al. Long-term results of operation for carcinoma of the stomach in T1/T2 stages: critical evaluation of the concept of Early Gastric Carcinoma of the stomach. J Am Coll Surg. 1995;181:389-396.

19) Isozaki H, Fujii K, Nomura E, et al. Prognostic factors of advanced gastric carcinoma without serosal invasion (pT2 gastric carcinoma). Hepatogastroenterology. 1999;46:26692672. 
20) Nitti D, Marchet A, Mocellin S, et al. Prognostic value of subclassification of T2 tumours in patients with gastric cancer. Br J Surg. 2009;96:398-404.

21) Edge SB, Byrd DR, Compton CC, Fritz AG, Greene FL, Trotti A. AJCC Cancer Staging Manual (7th ed). Springer-Verlag: New York, 2010.

22) Kaplan EL, Meier P. Nonparametric estimation from incomplete observations. J Am Stat Assoc. 1958;53:457-481.

23) Cox DR. Regression models and life-tables. J R Stat Soc B. 1972;34:187-220.

24) Newcombe R.G. Interval Estimation for the Difference Between Independent Proportions: Comparison of Eleven Methods. Statistics in Medicine. 1998;17:873-890.

25) Siewert JR, Bittcher K, Stein HJ, et al. Relevant prognostic factors in gastric cancer. Tenyear results of the German Gastric cancer Study. Ann Surg. 1998;228:449-461. 


\section{Figure legends}

FIGURE 1. Relationship between number of metastatic lymph nodes and number of examined lymph nodes in T2 (blue line), T3 (red line) and T4a tumors (gray line).

FIGURE 2. Kaplan-Meier survival curves for T2 and T3 tumor stage without (upper panel) and with (lower panel) nodal involvement. 
TABLE 1. Univariate analysis of Overall Survival (OS) in 686 patients with T2/T3 gastric cancer categories

\begin{tabular}{|c|c|c|c|c|c|c|}
\hline Factor & $\begin{array}{c}\text { No. } \\
\text { Patients }\end{array}$ & $\begin{array}{c}\text { T2 } \\
\text { No. }(\%) \\
\end{array}$ & $\begin{array}{c}\text { T3 } \\
\text { No. }(\%) \\
\end{array}$ & $\begin{array}{c}\text { 5-year OS } \\
\text { Rate }(\%)\end{array}$ & $95 \% \mathrm{CI}$ & P-value \\
\hline $\begin{array}{l}\mathrm{F} \\
\mathrm{M}\end{array}$ & $\begin{array}{l}280 \\
406\end{array}$ & $\begin{array}{l}107(39.6) \\
163(60.4)\end{array}$ & $\begin{array}{l}173(41.6) \\
243(58.4)\end{array}$ & $\begin{array}{l}59.7 \\
53.7\end{array}$ & $\begin{array}{l}54.0-66.0 \\
52.4-62.7\end{array}$ & 0.439 \\
\hline $\begin{aligned} & \text { Age }<65 \\
& \geq 65 \\
&\end{aligned}$ & $\begin{array}{l}249 \\
437\end{array}$ & $\begin{array}{r}88(32.6) \\
182(67.4)\end{array}$ & $\begin{array}{l}161(38.7) \\
255(61.3)\end{array}$ & $\begin{array}{l}64.4 \\
54.8\end{array}$ & $\begin{array}{l}58.4-71.1 \\
50.1-60.0\end{array}$ & 0.00237 \\
\hline $\begin{array}{l}\text { Lower } \\
\text { Middle } \\
\text { Upper } \\
\text { Cardias } \\
\text { Multicentric } \\
\end{array}$ & $\begin{array}{l}342 \\
195 \\
93 \\
37 \\
19 \\
\end{array}$ & $\begin{array}{r}146(54.1) \\
85(31.5) \\
28(10.4) \\
6(2.2) \\
5(1.9) \\
\end{array}$ & $\begin{array}{r}196(47.1) \\
110(26.4) \\
65(15.6) \\
31(7.5) \\
14(3.4) \\
\end{array}$ & $\begin{array}{l}59.1 \\
64.3 \\
37.1 \\
46.6 \\
56.8 \\
\end{array}$ & $\begin{array}{l}53.9-64.7 \\
57.4-71.9 \\
37.1-59.6 \\
31.0-70.1 \\
38.1-84.9 \\
\end{array}$ & 0.319 \\
\hline $\begin{array}{l}\text { Surgery } \\
\text { Gastric resection } \\
\text { Total gastrectomy } \\
\text { Extended total } \\
\text { gastrectomy } \\
\end{array}$ & $\begin{array}{r}427 \\
244 \\
15\end{array}$ & $\begin{array}{r}186(68.9) \\
84(31.1) \\
0(0)\end{array}$ & $\begin{array}{r}241(57.9) \\
161(38.7) \\
15(3.4)\end{array}$ & $\begin{array}{l}59.9 \\
56.0 \\
46.2\end{array}$ & $\begin{array}{l}55.3-65.0 \\
49.5-63.3 \\
15.3-78.2\end{array}$ & 0.492 \\
\hline $\begin{array}{l}\text { D1 } \\
\text { D2 } \\
\text { D3 } \\
\end{array}$ & $\begin{array}{c}96 \\
487 \\
103 \\
\end{array}$ & $\begin{array}{r}48(17.8) \\
188(69.6) \\
34(12.6) \\
\end{array}$ & $\begin{array}{r}48(11.5) \\
299(71.9) \\
69(16.6) \\
\end{array}$ & $\begin{array}{l}49.0 \\
59.3 \\
60.9 \\
\end{array}$ & $\begin{array}{l}39.3-61.0 \\
54.9-64.0 \\
50.4-73.5 \\
\end{array}$ & 0.02 \\
\hline $\begin{array}{l}\text { Grading } \\
\qquad \begin{array}{r}\text { G1 } \\
\text { G2 } \\
\text { G3 } \\
\text { G4 } \\
\text { G.x }\end{array}\end{array}$ & $\begin{array}{c}52 \\
258 \\
294 \\
23 \\
59\end{array}$ & $\begin{array}{r}32(11.9) \\
109(40.4) \\
92(34.1) \\
4(1.5) \\
33(12.2) \\
\end{array}$ & $\begin{array}{r}20(4.8) \\
149(35.8) \\
202(48.6) \\
19(4.6) \\
26(6.3) \\
\end{array}$ & $\begin{array}{l}59.3 \\
58.9 \\
58.4 \\
59.6 \\
53.8\end{array}$ & $\begin{array}{l}46.2-76.1 \\
52.8-65.5 \\
52.8-64.7 \\
41.7-84.1 \\
41.9-69.1 \\
\end{array}$ & 0.977 \\
\hline $\begin{array}{l}\text { Lauren } \\
\text { Intestinal } \\
\text { Diffuse } \\
\text { Mixed } \\
\end{array}$ & $\begin{array}{c}517 \\
140 \\
29 \\
\end{array}$ & $\begin{array}{r}198(73.3) \\
52(19.4) \\
20(7.3) \\
\end{array}$ & $\begin{array}{r}319(76.7) \\
88(21.2) \\
9(2.1) \\
\end{array}$ & $\begin{array}{l}61.8 \\
52.2 \\
53.8 \\
\end{array}$ & $\begin{array}{l}57.3-66.6 \\
47.0-57.1 \\
37.0-78.4 \\
\end{array}$ & 0.438 \\
\hline $\begin{array}{r}\text { T-stage } \\
\text { T2 } \\
\text { T3 }\end{array}$ & $\begin{array}{l}270 \\
416\end{array}$ & - & - & $\begin{array}{l}67.3 \\
52.3\end{array}$ & $\begin{array}{l}61.1-72.8 \\
47.0-57.4\end{array}$ & $<0.0001$ \\
\hline $\begin{array}{l}\text { N-stage } \\
\text { N0 } \\
\text { N+ } \\
\text { N1 } \\
\text { N2 } \\
\text { N3a } \\
\text { N3b } \\
\end{array}$ & $\begin{array}{c}279 \\
407 \\
126 \\
154 \\
84 \\
43 \\
\end{array}$ & $\begin{array}{r}149(55.2) \\
121(44.8) \\
52(19.3) \\
49(18.1) \\
18(6.7) \\
2(0.7) \\
\end{array}$ & $\begin{array}{r}130(31.3) \\
286(68.7) \\
74(17.8) \\
105(25.2) \\
66(15.9) \\
41(9.9) \\
\end{array}$ & $\begin{array}{c}65.7 \\
53.1 \% \\
68.3 \\
53.4 \\
45.7 \\
13.9 \\
\end{array}$ & $\begin{array}{r}60.1-71.8 \\
48.2-58.6 \\
60.3-77.4 \\
45.5-62.6 \\
35.6-58.6 \\
4.8-40.3 \\
\end{array}$ & $<0.0001$ \\
\hline
\end{tabular}


TABLE 2. Pattern of lymph node involvement according to T category in 686 gastric cancer patients

\begin{tabular}{|c|c|c|c|c|c|c|c|c|c|c|c|c|}
\hline \multirow{3}{*}{ T Stage } & \multicolumn{10}{|c|}{ N Stage } & & \\
\hline & \multicolumn{2}{|c|}{ No } & \multicolumn{2}{|c|}{ N1 } & \multicolumn{2}{|c|}{$\mathbf{N 2}$} & \multicolumn{2}{|c|}{ N3a } & \multicolumn{2}{|c|}{ N3b } & \multicolumn{2}{|c|}{ Total } \\
\hline & $\mathrm{n}$ & $\%$ & $\mathrm{n}$ & $\%$ & $\mathrm{n}$ & $\%$ & $\mathrm{n}$ & $\%$ & $\mathrm{n}$ & $\%$ & $\mathrm{n}$ & $\%$ \\
\hline $\mathrm{T} 2$ & 149 & 55.2 & 52 & 19.3 & 49 & 18.1 & 18 & 6.7 & 2 & 0.7 & 270 & 39.4 \\
\hline T3 & 130 & 31.3 & 74 & 17.8 & 105 & 25.2 & 66 & 15.9 & 41 & 9.9 & 416 & 60.6 \\
\hline Total & 279 & 40.7 & 126 & 18.4 & 154 & 22.4 & 84 & 12.2 & & 6.3 & 686 & 100 \\
\hline
\end{tabular}


TABLE 3. 5-years Overall Survival (OS) according to T2/T3 category and N category

\begin{tabular}{|c|c|c|c|c|c|}
\hline N stage & \multicolumn{2}{|l|}{ T2 } & \multicolumn{2}{|l|}{ T3 } & \\
\hline & 5-yr OS Rate (\%) & $95 \% \mathrm{CI}$ & 5-yr OS Rate (\%) & $95 \% \mathrm{CI}$ & $\mathrm{P}$ \\
\hline N0 & 68.0 & $60.6-76.2$ & 63.1 & $54.9-72.6$ & 0.015 \\
\hline $\mathbf{N +}$ & 66.5 & $58.1-75.9$ & 47.2 & $41.3-54.0$ & $<0.001$ \\
\hline N1 & 71.1 & $59.4-85.1$ & 66.4 & $56.0-78.8$ & 0.076 \\
\hline $\mathbf{N 2}$ & 61.2 & $48.2-77.6$ & 49.9 & $40.4-61.5$ & 0.264 \\
\hline N3a & 69.1 & $49.7-96.2$ & 39.1 & $28.3-54.0$ & 0.032 \\
\hline N3b & - & - & 12.5 & $4.0-38.4$ & NA \\
\hline
\end{tabular}


TABLE 4. Multivariate survival analysis of 686 gastric cancer patients with T2/T3 categories

\begin{tabular}{|c|c|c|c|}
\hline Factor & P-value & HR & $95 \% \mathrm{CI}$ \\
\hline $\mathbf{T}$ & 0.005 & & \\
\hline T3 & 0.005 & 1.420 & $1.110-1.817$ \\
\hline D & $<0.0001$ & & \\
\hline D2 & 0.000722 & 0.597 & $0.443-0.805$ \\
\hline D3 & 0.808 & 0.952 & $0.641-1.413$ \\
\hline Age & $<0.0001$ & & \\
\hline$\geq 65$ & $<0.0001$ & 1.677 & $1.323-2.126$ \\
\hline
\end{tabular}

$\mathrm{HR}=$ Hazard Ratio $\mathrm{CI}=$ confidence interval 


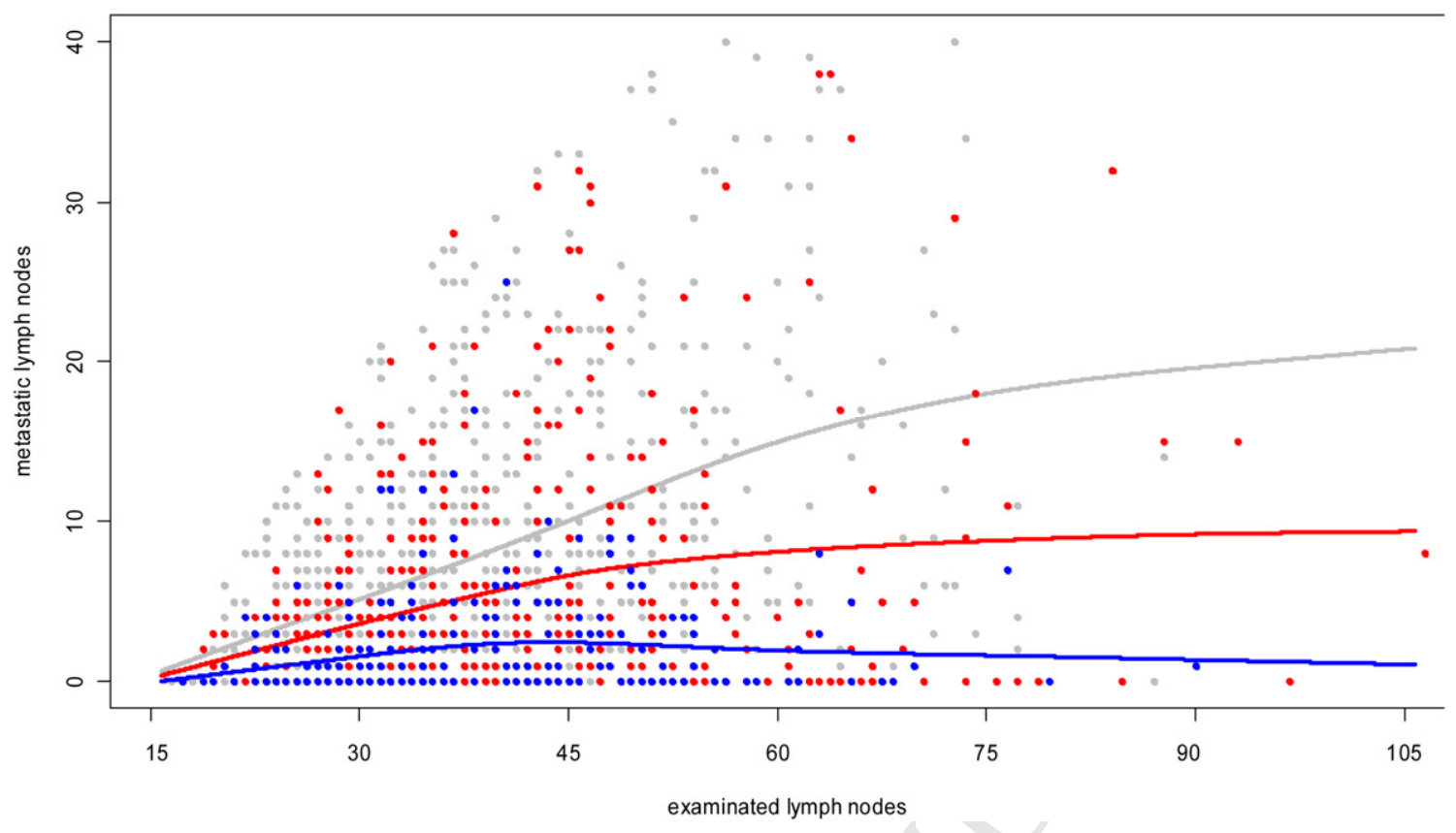


Figure 2 - upper panel

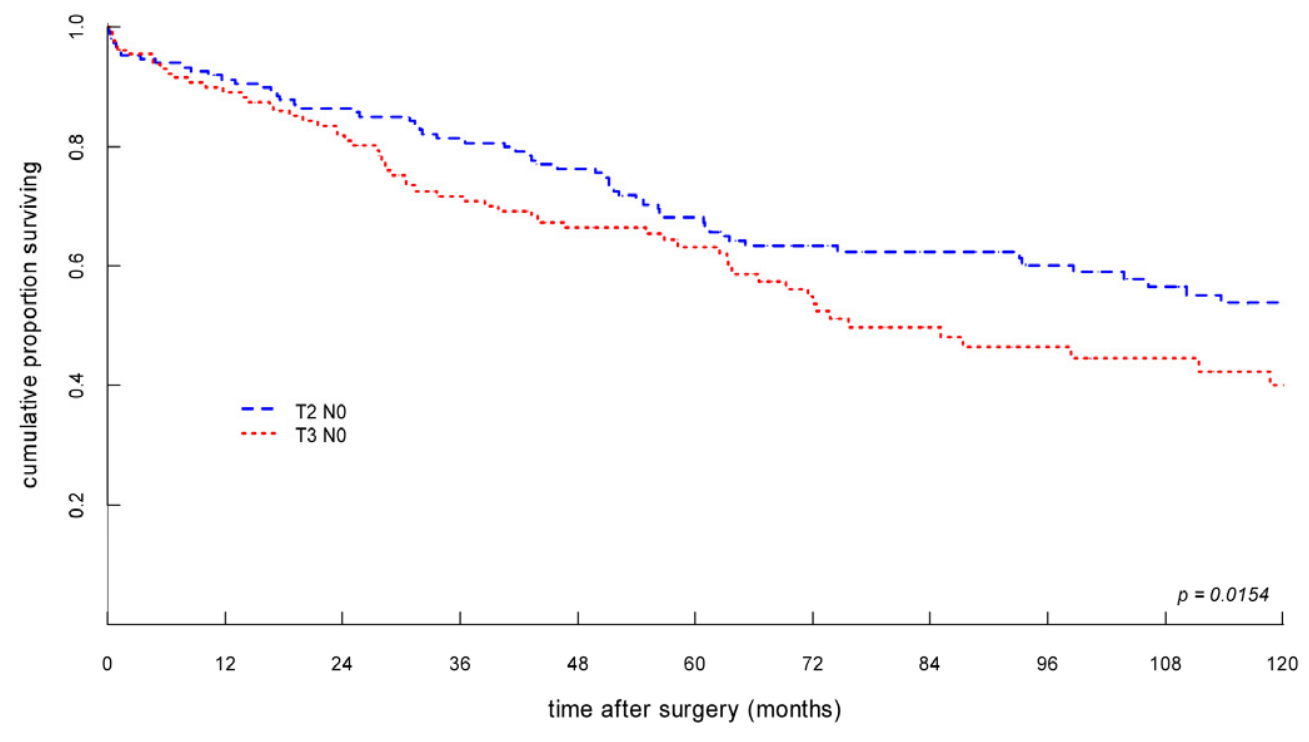

Figure 2 - lower panel

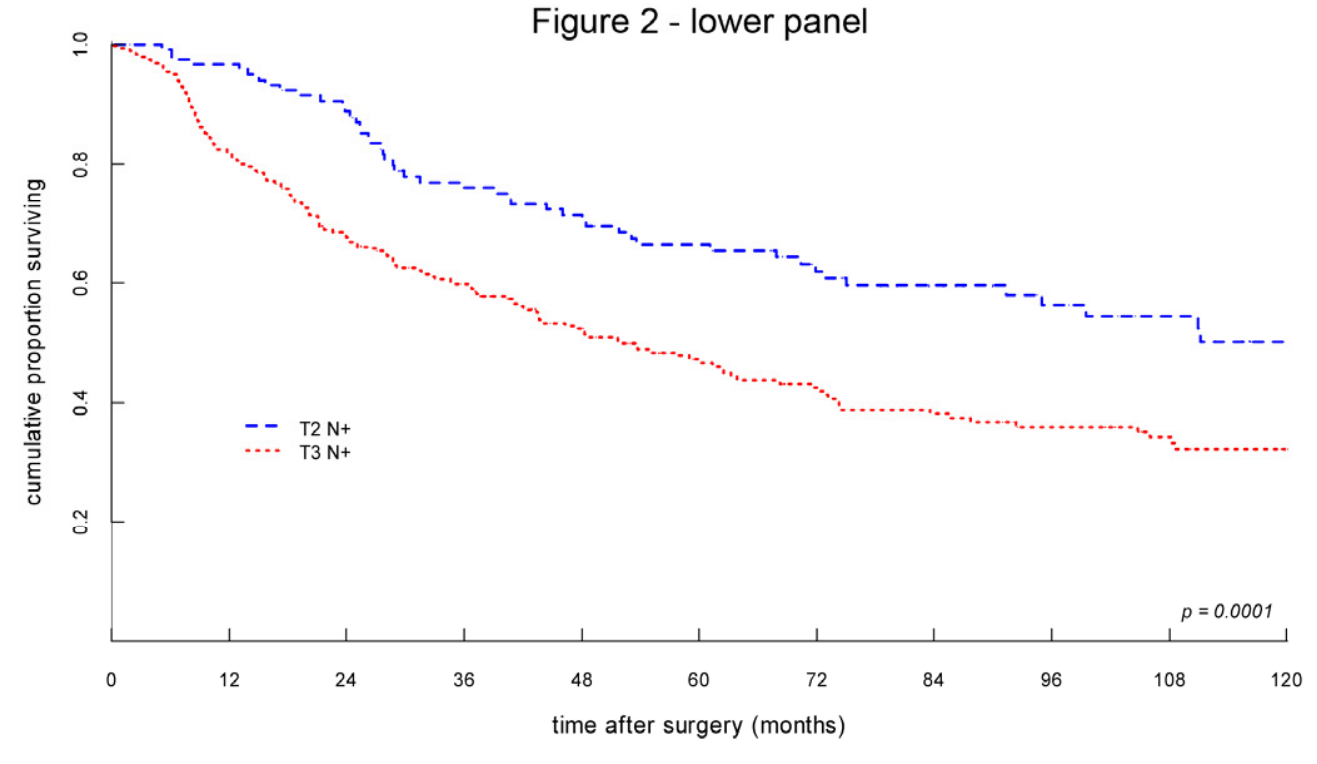

